\title{
PEMILIHAN FRAMEWORK APLIKASI WEB BERBASIS JAVA MENGGUNAKAN ANALYTICAL HIERARCHY PROCESS (AHP)
}

\author{
Lukman Azhari \\ Program Studi Informatika \\ Fakultas Teknik Universitas Muhammadiyah Tangerang \\ Jl. Perintis Kemerdekaan 1/33 Cikokol Kota Tangerang \\ Lukmanazhari85@gmail.com
}

\begin{abstract}
Currently, many web application frameworks that available in the internet, we know from wikipedia that more than 20 java frameworks for developing web application. Frameworks is a developed base of related design or related architecture. A framework provides a set of libraries or classes that used by us to developing a web application, they will cooperate each others to accomplish certain tasks in the intended domain [SCHWABE 2001]. Decision makers can choose application frameworks that can be implemented in information system development. In this research writer will examine features in framework Java server faces, Struts, and Spring MVC with using ISO 9126 for getting criteria in choosing framework. This research will compare hierarchically with approaching Analytical Hierarchy Process (AHP). Finally, from the result of this research we got the best alternatif from Java framework. The best java framework is Java Framework Spring MVC in comparison of Java Framework Java Server Faces and Java Framework Struts. So, it is very clear that Java Framework Spring MVC is the best framework which supported in developing information system.
\end{abstract}

Keyword : Framework, Java Server Faces, Spring MVC, ISO 9126, Analytical Hierarchy Process.

\section{PENDAHULUAN}

A. Latar Belakang

Internet telah membawa revolusi besar pada dunia komunikasi dan komputer. Internet dengan berbagai kapabilitas dan aneka layanan yang disuguhkannya segera menjangkau seluruh pelosok dunia dalam waktu relatif singkat, suatu mekanisme penghamburan informasi, media kolaborasi dan interaksi diantara individu dan komputer tanpa terbatas lokasi geografis dan waktu.

Internet menggunakan teknologi World Wide Web (WWW). Definisi tentang WWW yang dirangkum dari beberapa situs termasuk wikipedia adalah sebuah sistem dimana informasi dalam bentuk teks, gambar, suara, dan lain-lain dipresentasikan dalam bentuk hypertext dan dapat diakses oleh perangkat lunak yang disebut browser. Informasi di web pada umumnya ditulis dalam format HTML.
Informasi lainnya disajika dalam bentuk grafis (dalam format GIF, JPG, PNG), suara (dalam format AU, WAV), dan objek multimedia lainnya (seperti MIDI, Shockwave, Quicktime Movie, 3D World).

Bahasa pemrograman java telah dikembangkan oleh perusahaan informatika terkemuka, Sun Microsystem, dalam projek rahasianya yang disebut dengan kode "green project". Hingga saat ini perkembangan bahasa pemrograman java, yang mempunyai moto "Write Once Run Everywhere", merupakan salah satu bahasa pemrograman terkenal didunia untuk mengembangkan aplikasi ataupun alat bantu.

Terpilihnya bahasa pemrograman java oleh pakar informatika, dikarenakan bahasa pemrograman java mengimplementasikan pemrograman berorientasi objek secara penuh, handal dan dapat digunakan disemua platform. 
Saat ini banyak java frameworks yang tersedia di internet, dari situs wikipedia didapat lebih dari 20 java frameworks. Software frameworks dikembangkan menurut desain atau arsitektur. Pengembang atau pembuat software frameworks memilih arsitektur aplikasi yang dianggap terbaik bagi framework yang dibuatnya.

\section{B. Identifikasi Masalah}

Berdasarkan uraian latar belakang, dapat diidentifikasi permasalahannya adalah pemilihan framework yang tepat dalam pembangunan aplikasi.

\section{Rumusan Masalah}

Berdasarkan pemikiran diatas maka rumusan masalah adalah manakah yang terbaik dari tiga (3) Java Framework yang diuji yaitu Java Framework Struts, Java Framework Java Server Faces, dan Java Framework Spring $M V C$.

\section{Batasan Masalah}

Pada penelitian ini difokuskan pada tiga Java Framework yang berada pada 3 urutan teratas dari 10 Best Java Web Development Framework [LILYINX 2010] yaitu Struts sebagai urutan pertama, Java Server Faces sebagai urutan kedua dan Spring $M V C$ sebagai urutan ketiga.

\section{TINJAUAN PUSTAKA}

\section{A. Bahasa Pemrograman Java}

Java adalah sebuah platform teknologi pemrograman yang dikembangkan oleh Sun Microsystem. Pertama kali di-"release "tahun 1991 dengan nama kode "Oak". Kemudian tahun 1995 nama kode "Oak" diganti menjadi "Java". Yang memotivasi Java dibuat adalah untuk membuat sebuah bahasa pemrograman yang portable dan independent terhadap platform (platform independent). Java dapat membuat perangkat lunak yang dapat ditanamkan (embedded) pada berbagai mesin dan peralatan konsumer, seperti handphone, microwave, remote control, dan lain-lain. Hal ini kemudian Java memiliki konsep yang disebut "write once run anywhere".

\section{B. Framework}

Framework adalah suatu struktur dasar konseptual yang memecahkan atau menunjuk isu kompleks. Ini merupakan definisi yang sangat luas yang dipergunakan sebagai kata pemicu, terutama dalam konteks perangkat lunak.

Pengembangan software saat ini menghendaki program yang re-usable, berbasis komponen dan program berorientasi object. Paradigma praktisi IT kini berubah dari yang awalnya melakukan peng-kodean (coding) dari awal "code from stretch" menjadi pengembang yang cenderung membangun sebuah aplikasi berdasarkan kerangka kerja atau framework.

Programmer dapat menggunakan framework yang sudah ada dalam pembuatan suatu aplikasi program. Dengan menggunakan framework akan didapat banyak manfaat diantaranya [3].

a. Mengurangi Waktu Pengembangan aplikasi (Reduce time to market): Mempercepat pengembangan aplikasi, dengan meminimalisasi penulisan kode program.

b. Pemeliharaan (Maintenance): Kode dan logika yang terdapat dalam aplikasi tertata dengan rapi, terjaga tetap teratur, mudah dibaca sehingga akan mempermudah proses maintenance.

c. Kehandalan (Reliability): Dengan adanya kode program yang dapat digunakan kembali (reuse) maka akan menaikan derajat reliabilitas kode program dibandingkan dengan membuat kode program baru.

d. Standar (Standard): Framework dibangun dengan aturan penulisan kode program atau kode standard yang dibuat oleh penciptanya. Dengan adanya standarisasi kode ini maka dapat memudahkan pengguna dalam membuat aplikasi.

e. Sederhana (Simple): Kode dan logika yang terdapat dalam aplikasi tertata dengan rapi, terjaga tetap teratur, mudah dibaca sehingga akan mempermudah proses maintenance-nya.

\section{ISO 9126}

Kualitas untuk membuat software dapat dinilai melalui ukuran-ukuran dan metode- 
metode tertentu, serta melalui pengujianpengujian software. Salah satu tolak ukur kualitas perangkat lunak adalah ISO 9126, yang dibuat oleh International Organization for Standardization (ISO) dan International Electrotechnical Commission (IEC). ISO 9126 mendefinisikan kualitas produk perangkat lunak, model, karakteristik mutu, dan metrik terkait digunakan untuk mengevaluasi dan menetapkan kualitas sebuah produk software.

Dalam ISO 9126 menetapkan 6 karakteristik kualitas yaitu :
a. Fungsionalitas
(Functionality):
Kemampuan menutupi fungsi produk perangkat lunak yang menyediakan kepuasan kebutuhan user.

b. Kehandalan (Reliability): Kemampuan perangkat lunak untuk dapat diandalkan, seyogyanya dapat berfungsi $100 \%$ waktu.

c. Penggunaan (Usability): Kemampuan yang berhubungan dengan penggunaan perangkat lunak.

d. Efisiensi (Efficiency): Kemampuan yang berhubungan dengan sumber daya fisik yang digunakan ketika perangkat lunak dijalankan.

e. Pemeliharaan (Maintainability): Kemampuan yang dibutuhkan untuk membuat perubahan perangkat lunak.

f. Portabilitas (Portability): Kemampuan yang berhubungan dengan kemampuan perangkat lunak untuk dapat dikirim ke lingkungan berbeda.

\section{METODOLOGI PENELITIAN}

Proses Hirarki Analitik (AHP) dikembangkan oleh Dr. Thomas L. Saaty dari Wharton School of Business pada tahun 1970an untuk mengorganisasikan informasi dan judgement dalam memilih alternatif yang paling disukai [4]. Dengan menggunakan AHP, suatu persoalan yang akan dipecahkan dalam suatu kerangka berpikir yang terorganisir, sehingga memungkinkan dapat diekspresikan untuk mengambil keputusan yang efektif atas persoalan tersebut. Persoalan yang kompleks dapat disederhanakan dan dipercepat proses pengambilan keputusannya.

\section{ANALISIS DAN PEMBAHASAN}

Proses pengolahan, analisis data, interpretasi data dan implikasi penelitian yang didahului dengan menentukan elemen-elemen yang signifikan pada masing-masing level, yaitu pada level I berisi kriteria dari pemilihan framework aplikasi web berbasis Java, pada level II ditentukan kriteria-kriteria yang terkait pada kriteria level I, dan pada level III berisi alternatif pemilihan framework aplikasi web berbasis Java. Pada masing-masing level penentuan elemen dilakukan pada karakteristik kualitas dari ISO 9126 yang dibuat oleh International Organization for Standardization (ISO) dan International Electrotechnical Commission (IEC).

Dalam penelitian ini terdapat karakteristik responden ahli yang dapat ditinjau dari berbagai segi, diantaranya :

1. Responden berdasarkan Jenis Kelamin

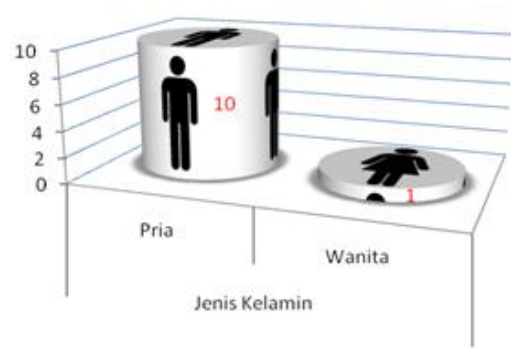

Gambar 3.1 Grafik Jumlah Responden berdasarkan Jenis Kelamin

2. Responden Berdasarkan Usia

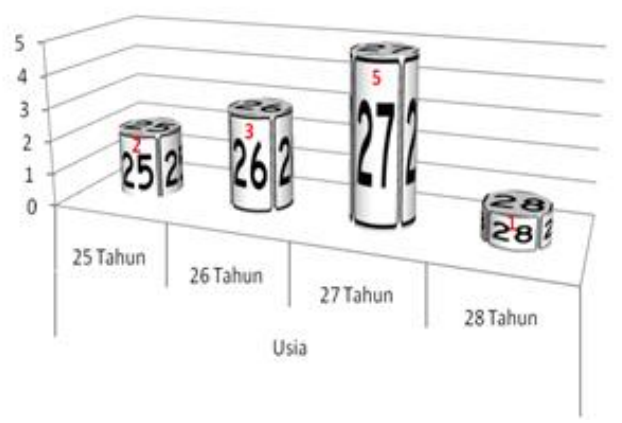

Gambar 3.2 Grafik Jumlah Responden Berdasarkan Usia

3. Responden Berdasarkan Pendidikan Terakhir 


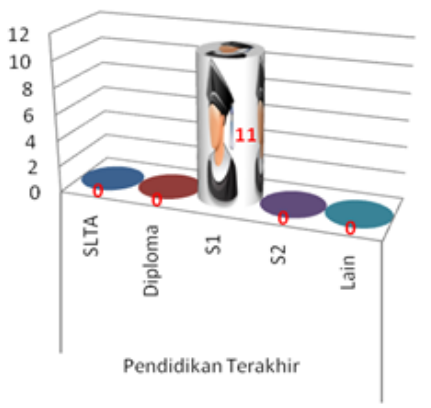

- Pendidikan Terakhirs framework aplikasi web berbasis Java.

= Pendidikan Terakhir [

? Pendidikan Terakhir $s$

= Pendidikan Terakhir \$

= Pendidikan Terakhir L

Gambar 3.3 Grafik Jumlah Responden

Berdasarkan Pendidikan Terakhir

4. Responden Berdasarkan Pekerjaan

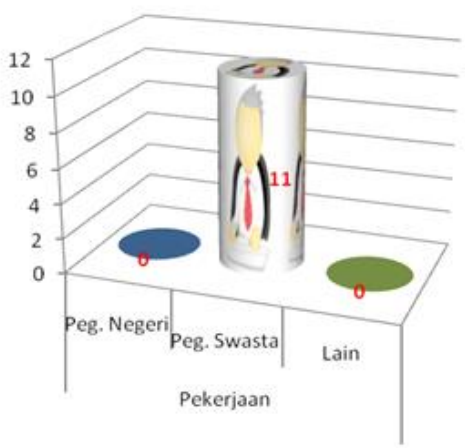

Gambar 3.4 Grafik Jumlah Responden Berdasarkan Pekerjaan

5. Responden Berdasarkan Jabatan

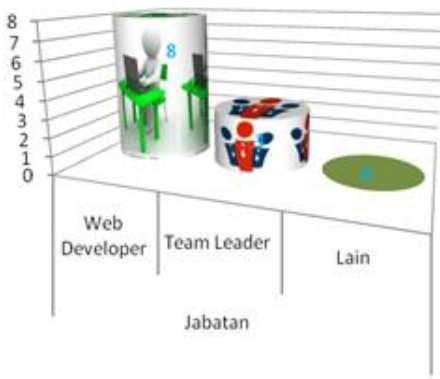

Gambar 3.5 Grafik Jumlah Responden Berdasarkan Jabatan

\section{Bobot Kriteria}

Analisis pendapat gabungan para responden menunjukkan bahwa kriteria "Usability" (nilai bobot 0,263 atau sebanding dengan $26,3 \%$ dari total kriteria) merupakan kriteria yang paling penting dari kriteria yang dimiliki oleh sebuah aplikasi java framework, yang mempengaruhi pengambil keputusan dalam pemilihan

Berikut ini disajikan bobot masing-masing kriteria yang mempengaruhi pemilihan framework aplikasi web berbasis Java :

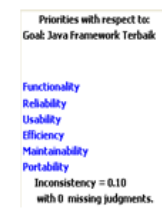

Gambar 3.6 Kriteria dalam pemilihan framework aplikasi web berbasis Java beserta nilai bobotnya

Dari nilai bobot prioritas kriteria dalam pemilihan framework aplikasi web berbasis Java diatas, maka didapat grafik seperti dibawah ini :

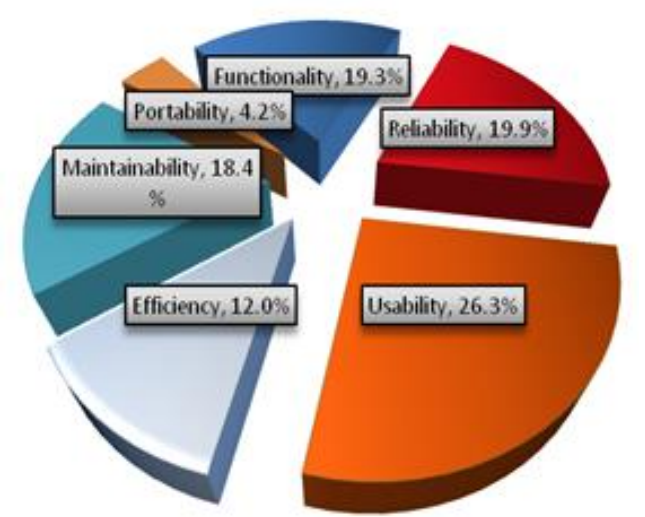

Gambar 3.7 Grafik Nilai Bobot prioritas Kriteria dalam pemilihan framework aplikasi web berbasis Java

\section{Inconsistency Ratio (CR)}

Nilai rasio inkonsistensi yang didapat sama dengan 0,1 sebagai batas maksimum nilai rasio inkonsistensi. Dengan demikian hasil perhitungan gabungan data responden untuk perbandingan berpasangan bagi kriteria cukup konsisten.

Setelah melalui proses pengisian kuesioner oleh para responden ahli, dan melalui perhitungan penggabungan data responden ahli 
dengan menggunakan software Expert Choice 2000 diperoleh nilai bobot global prioritas alternatif berdasarkan sasaran pemilihan framework aplikasi web berbasis Java seperti yang disajikan pada grafik berikut :

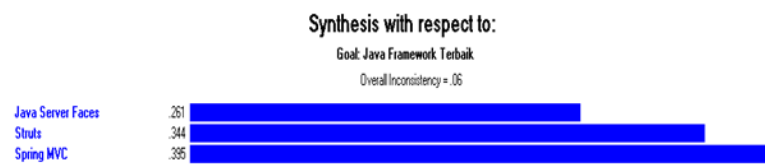

Gambar 3.8 Grafik Nilai Bobot Global

Prioritas Alternatif berdasarkan Sasaran Pemilihan Framework Aplikasi Web Berbasis Java

Dari nilai bobot global prioritas Alternatif berdasarkan Sasaran Pemilihan Framework Aplikasi Web Berbasis Java diatas, maka didapat grafik seperti dibawah ini :

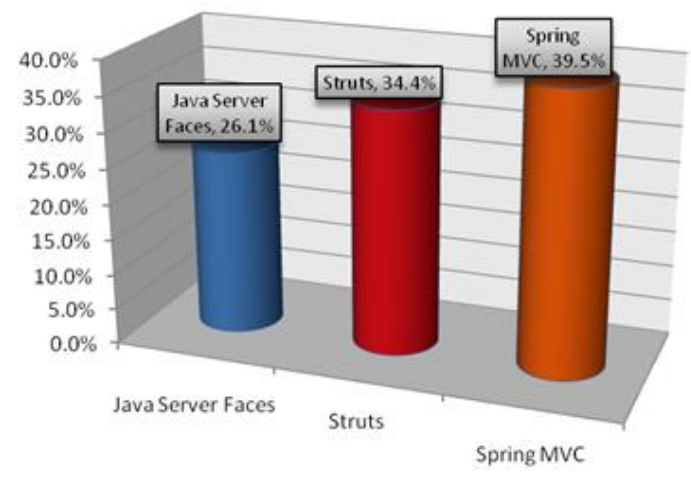

Gambar 3.9 Grafik Nilai Bobot Global Prioritas Alternatif Berdasarkan Sasaran Pemilihan Framework Aplikasi Web Berbasis Java

Berikut adalah grafik performansi sensitifitas dari alternatif - alternatif yang dibandingkan berdasarkan kriteria - kriteria dan keseluruhan kriteria (Overall) :

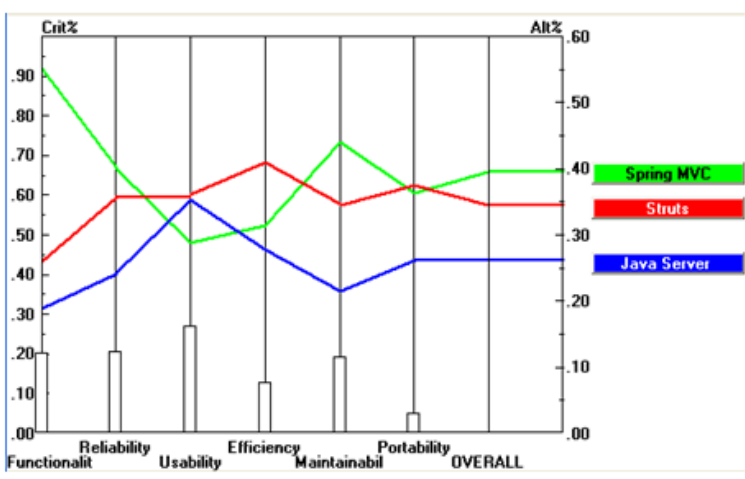

Gambar 3.10 Grafik Performansi Sensitifitas alternatif berdasarkan kriteria - kriteria dan keseluruhan kriteria (Overall)

Dilihat dari keseluruhan kriteria (Overall) alternatif Spring MVC berada pada posisi pertama dengan nilai 39,5\% lalu disusul oleh Struts yang berada pada posisi kedua dengan nilai $34,4 \%$ dan pada posisi terakhir ditempati oleh Java Server Faces dengan nilai 26,1\%.

\section{KESIMPULAN}

A. Kesimpulan

Dari hasil penelitian didapat bahwa Java Framework Spring MVC adalah alternatif pilihan tertinggi pada pemilihan framework aplikasi web berbasis Java dibandingkan dengan Java Framework Java Server Faces dan Java Framework Struts. Hasil ini tidak sesuai dengan hipotesa awal atau $\mathrm{H} 1$ ditolak yaitu diduga Java Framework Struts relatif lebih baik dari Java Framework Java Server Faces dan Java Framework Spring MVC.

\section{REFERENSI}

[1] Benjamin Zeiss, et.al, "Applying the ISO 9126 Quality Model to Test Specifications", the ASTD International Conference, Germany 2008.

[2] Java Education Network Indonesia, "Web Programming-Bab $9-J S F ”$, JENI, Jakarta 2010.

[3] Landin, Niklas \& Niklasson Axel. Development of Object Oriented Frameworks, 1995.

[4] Marimin, Teknik dan Aplikasi Pengambilan Keputusan Kriteria 
Majemuk. PT. Gramedia Widiasarana Indonesia. Jakarta, 2005.

[5] Peng Wang, "Comparison of Four Popular Java Web Framework Implementations: Struts1.X, WebWork2.2X, Tapestry4, JSF1.2", Institute of China, China 2008.

[6] Praveen Gupta and M.C. Govil, "MVC Design Pattern for the multi framework distributed applications using XML, spring and struts framework", Institute of India, India 2010.

[7] Schwabe, Daniel \& Rossi, Gustavo Rossi \& Esmeraldo, Luiselena dan Lyardet, Fernando. "Web Design Framework: An approach to improve reuse in Web applications", Departemento de Informatica,PUC-Rio,Brazil 